\title{
Cyclosporin as initial treatment for Crohn's disease
} S Nicholls, P Domizio, C B Williams, A Dawnay, C P Braegger, T T MacDonald,
J A Walker-Smith

\begin{abstract}
Childhood Crohn's disease may cause significant morbidity. $T$ cell activation is considered to be central to Crohn's disease pathology, and as cyclosporin is a powerful inhibitor of $T$ cell activation, and has been used in adult Crohn's disease with encouraging results, it may offer the prospect of remission if given early in the course of disease. Children with newly diagnosed Crohn's disease or those relapsing off treatment were therefore given cyclosporin or conventional treatment (enteral nutrition or corticosteroids) by random allocation. Evaluation was performed initially and at two months.

Twenty four children were studied (10 on cyclosporin and 14 on conventional treatment; one child on cyclosporin withdrew). Significant clinical improvement occurred in the group on conventional treatment, but not in the cyclosporin group. Colonoscopic improvement was noted in 5/9 on cyclosporin and 8/14 on conventional treatment, but neither group produced a significant fall in median colonoscopic index. Histological improvement was seen in 7/8 on cyclosporin and 8/13 on conventional treatment, but cyclosporin was not significantly better.

Cyclosporin produced improved clinical and histological appearance without matched improvement in blood disease indices. It was not better than conventional treatment, and simple oral administration is probably not suitable for newly diagnosed patients with Crohn's disease. (Arch Dis Child 1994; 71: 243-247)
\end{abstract}

St Bartholomew's Hospital, West Smithfield, London EC1A 7BE, Department of Paediatric Gastroenterology $S$ Nicholls C B Williams C P Braegger $T$ T MacDonald J A Walker-Smith

Department of Histopathology P Domizio

Department of Chemical Pathology A Dawnay

Correspondence to: Professor Walker-Smith. Accepted 28 April 1994
Crohn's disease in childhood is a serious disorder with a high morbidity that includes delayed puberty, impaired growth, and an eventual need for surgery in $50 \%$ of children five years after initial diagnosis. ${ }^{1}$ Immunological mechanisms are known to have a role in tissue damage, ${ }^{2}$ and there is accumulating evidence to suggest that a mucosal $\mathrm{T}$ cell hypersensitivity response is central in Crohn's pathology. ${ }^{3}$ Cyclosporin is a powerful inhibitor of $T$ cell activation and is the drug of choice to prevent rejection in organ transplant. Thus, there is a sound theoretical basis for the use of cyclosporin in Crohn's disease. In addition, cyclosporin has been shown to be effective in a number of disorders thought to be autoimmune in nature, ${ }^{45}$ and there have been a number of centres reporting successful use of cyclosporin in small uncontrolled groups of adults with Crohn's disease. ${ }^{6-9}$ The only large multicentre placebo controlled study reported a significant improvement in adult patients with Crohn's disease given cyclosporin at initial evaluation. ${ }^{10}$ Here we report our findings on the use of cyclosporin as a primary therapeutic modality in children with Crohn's disease.

\section{Patients and methods}

Twenty four children with newly diagnosed or relapsing active Crohn's disease were randomly allocated to receive either cyclosporin or conventional treatment. Demographic details are given in the table. Active Crohn's was diagnosed if inflammation was seen at colonoscopy, on barium follow through, or on histology.

\section{EVALUATION}

On entry into the study, children were evaluated as follows: colonoscopy and mucosal biopsies, blood tests (full blood count, erythrocyte sedimentation rate (ESR), $C$ reactive protein (CRP), and albumin), and a barium follow through with acceleration and compression. ${ }^{11}$ Clinical activity was assessed using a modified Lloyd-Still index, ${ }^{12}$ which takes into account clinical examination findings, physical well being, and growth

Demographic details of children studied

\begin{tabular}{|c|c|c|c|}
\hline $\begin{array}{l}\text { Age } \\
\text { (years) }\end{array}$ & Sex & $\begin{array}{l}\text { Location } \\
\text { of disease }\end{array}$ & $\begin{array}{l}\text { No of } \\
\text { attacks }\end{array}$ \\
\hline \multicolumn{4}{|c|}{ Conventional treatment } \\
\hline $12 \cdot 7$ & $\mathbf{M}$ & Ileocaecal & Second \\
\hline $10 \cdot 2$ & $\mathbf{M}$ & Colon & First \\
\hline $13 \cdot 3$ & $\mathbf{M}$ & Ileocolonic & Fourth \\
\hline $13 \cdot 3$ & $\mathbf{M}$ & Colon & Third \\
\hline $14 \cdot 7$ & $\mathbf{M}$ & Small bowel & Second \\
\hline $14 \cdot 7$ & $\mathbf{M}$ & Small bowel & First \\
\hline $14 \cdot 8$ & $\mathrm{~F}$ & Small bowel & Second \\
\hline $13 \cdot 0$ & $\mathbf{M}$ & Small bowel & First \\
\hline $12 \cdot 0$ & $\mathrm{~F}$ & Small bowel & First \\
\hline $11 \cdot 2$ & $\mathbf{M}$ & Small bowel & First \\
\hline $12 \cdot 7$ & $\mathrm{~F}$ & Small bowel & First \\
\hline $17 \cdot 0$ & $\mathbf{M}$ & Small bowel & Fourth \\
\hline \multicolumn{4}{|c|}{ Cyclosporin } \\
\hline $8 \cdot 5$ & $\mathbf{F}$ & Small bowel & First \\
\hline $14 \cdot 4$ & $\mathbf{M}$ & Ileocolonic & Third \\
\hline $14 \cdot 4$ & $\mathbf{M}$ & Small bowel & Serond \\
\hline $11 \cdot 2$ & $\mathrm{~F}$ & Panenteric & First \\
\hline 15.9 & $\mathbf{F}$ & Ileocolonic & Third \\
\hline $14 \cdot 9$ & $\mathbf{M}$ & Colon & Third \\
\hline $16 \cdot 7$ & $\mathbf{M}$ & Small bowel & Fifth \\
\hline $12 \cdot 9$ & $\mathbf{F}$ & Small bowel & Third \\
\hline $15 \cdot 1$ & $\mathrm{~F}$ & Ileocolonic & First \\
\hline $12 \cdot 0$ & $\mathrm{~F}$ & lleocolonic & Sixth \\
\hline $5 \cdot 1$ & $\mathbf{M}$ & Colon & First \\
\hline 13.5 & $\mathbf{F}$ & Ileocolonic & Second \\
\hline
\end{tabular}


data. In addition, all children were measured by a clinical auxologist using standard anthropometric techniques ${ }^{13}$ for height and weight at the beginning and the conclusion of the study period. Measurements were recorded on standard Tanner and Whitehouse growth charts. ${ }^{14}$

The treatment period was for eight weeks and then all investigations (except the barium study because, of the radiation dose) were repeated to assess the efficacy of the treatment. In order to assess colonoscopic improvement, the terminal ileum, colon, and rectum were scored from 0 to 3 according to whether the endoscopic appearance was adjudged by the endoscopist (CBW) to be normal, or to have mild, moderate, or severe inflammation. A reduction in overall score was taken to indicate improvement. A reduction of the score to zero meant that the appearance of the bowel had returned to normal.

In order to assess improvement in the biopsy specimens, two specimens were taken in the terminal ileum and 4-6 specimens throughout the length of the colon. The histological appearance was assessed blind by a histopathologist (PD). As there is no standard method for assessing the degree of inflammation in Crohn's disease, specimens were assessed blindly in pairs before and after treatment (without knowing the temporal sequence) and scored as worse, no change, improvement, and resolution of inflammation. Children with initially normal biopsy specimens, that is, those with more proximal small bowel Crohn's were not subjected to a second colonoscopy and biopsy.

\section{STATISTICS}

Changes from before to after values were assessed separately using the Wilcoxon signed rank test. The change between after and before values was compared between the two groups using the Mann-Whitney U test. The proportion improving in each group was compared using Fisher's exact test.

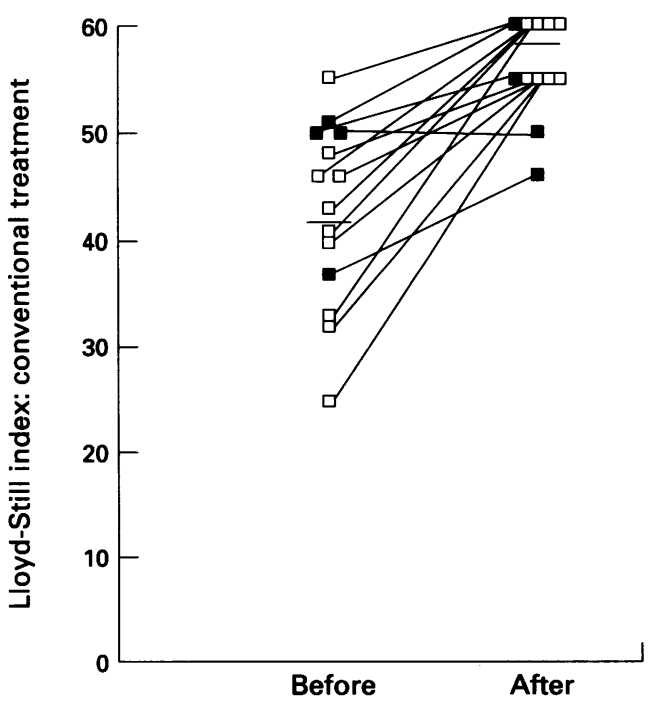

\section{TREATMENT REGIMEN}

When conventional treatment was allocated, the following scheme was used to determine treatment. With disease located in the small bowel alone enteral nutrition was given; with ileocolonic disease the treatment was with sulphasalazine with or without steroids; and with disease in the colon alone mesalazine with or without steroids was given.

\section{CYCLOSPORIN REGIMEN}

In patients treated with cyclosporin, the glomerular filtration rate (GFR) was measured (by the ${ }^{51} \mathrm{Cr}$-labelled EDTA method) to confirm normal initial renal function, and a baseline serum creatinine was measured. The initial dose was $5 \mathrm{mg} / \mathrm{kg}$ orally once daily. Weekly blood and serum creatinine concentrations were checked, with dose adjustment to try to achieve a trough concentration of 100-150 $\mu \mathrm{g} / \mathrm{l}$. (Trough concentrations were measured in whole blood by the parent compound specific assay, CYCLO-Trac SP, Incstar Ltd.) If the serum creatinine rose by more than $30 \%$ above baseline, the cyclosporin dose was reduced by half. After the treatment period, cyclosporin was stopped (that is, not tailed off). Recipients of cyclosporin underwent a second GFR measurement within 2-4 days of the final dose to reassess renal function.

\section{CONVENTIONAL TREATMENT REGIMEN}

Children to be treated with corticosteroids were commenced on 1-2 $\mathrm{mg} / \mathrm{kg} /$ day of prednisolone, and the dose was tapered in the usual fashion. If the child was to be treated with enteral nutrition, then they were assessed by the dietitian and prescribed a daily volume of enteral nutrition determined by their body weight. The preparations used were either the semielemental diet Flexical (Mead Johnson) or a specific polymeric diet (Nestle). The child took this as his/her sole source of nutrition for six weeks, after which the standard food reintroduction protocol was followed. ${ }^{15}$

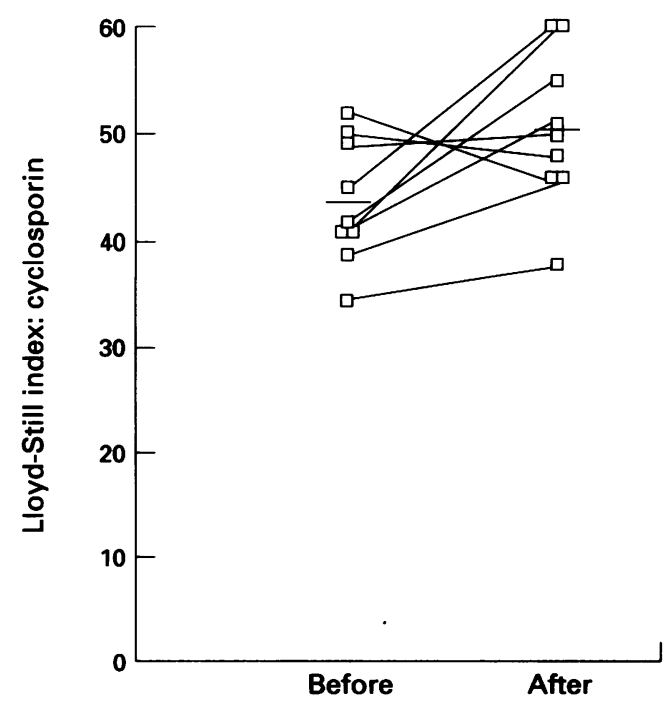

Figure 1 Changes in Lloyd-Still index before and after treatment. Filled squares indicate corticosteroid treated patients. Lines joining squares signify individual patients. 



Figure 2 Changes in ESR values before and after treatment. Filled squares indicate corticosteroid treated patients.

ETHICS

All parents gave informed written consent, and the study was approved by the $\mathrm{St}$ Bartholomew's Hospital ethical committee.

\section{Results}

One child in the cyclosporin group was withdrawn from the study because of clinical deterioration, and is not considered in the results or side effects. None were withdrawn from the conventional group.

\section{CLINICAL IMPROVEMENT}

Six out of nine $(67 \%)$ children treated with cyclosporin improved as assessed by the Lloyd-Still index (two to normal) compared with 13 out of $14(93 \%)$ treated conventionally (seven to normal) (fig 1).

The median Lloyd-Still index improved from 43.5 to 50.5 in the cyclosporin group compared with 43.0 to 57.5 on conventional treatment. The median improvement (95\% confidence interval, $\mathrm{CI}$ ) in the index was
6.5 (0 to 14) in the cyclosporin group (not significant, $p=0.051)$ compared with 12.0 (8.5 to $19 \cdot 5$ ) in the conventional group (significant, $\mathrm{p}<0.002$ ).

\section{COLONOSCOPIC IMPROVEMENT}

Five out of nine (56\%) children treated with cyclosporin improved (none to normal), compared with eight out of $14(57 \%)$ treated conventionally (one to normal). The median $(95 \% \mathrm{CI}$ ) activity score fell from 2.0 (1 to 4 ) to $1.0(0.5$ to 2$)$ in the cyclosporin group compared to a fall from $1.5(0.5$ to 3$)$ to 1.0 $(0.5$ to 1.5$)$ in the conventional group. The median decrease in activity score was -1.0 $(-2.5$ to 0$)$ for the cyclosporin group (not significant, $p=0.06$ ) compared with -0.5 $(-1.5$ to 0$)$ for the conventional group (not significant, $p=0 \cdot 11$ ). There was no significant difference between the changes $(p=0 \cdot 6)$.

\section{BIOPSY SPECIMEN IMPROVEMENT}

Seven out of eight $(87 \%)$ children treated with
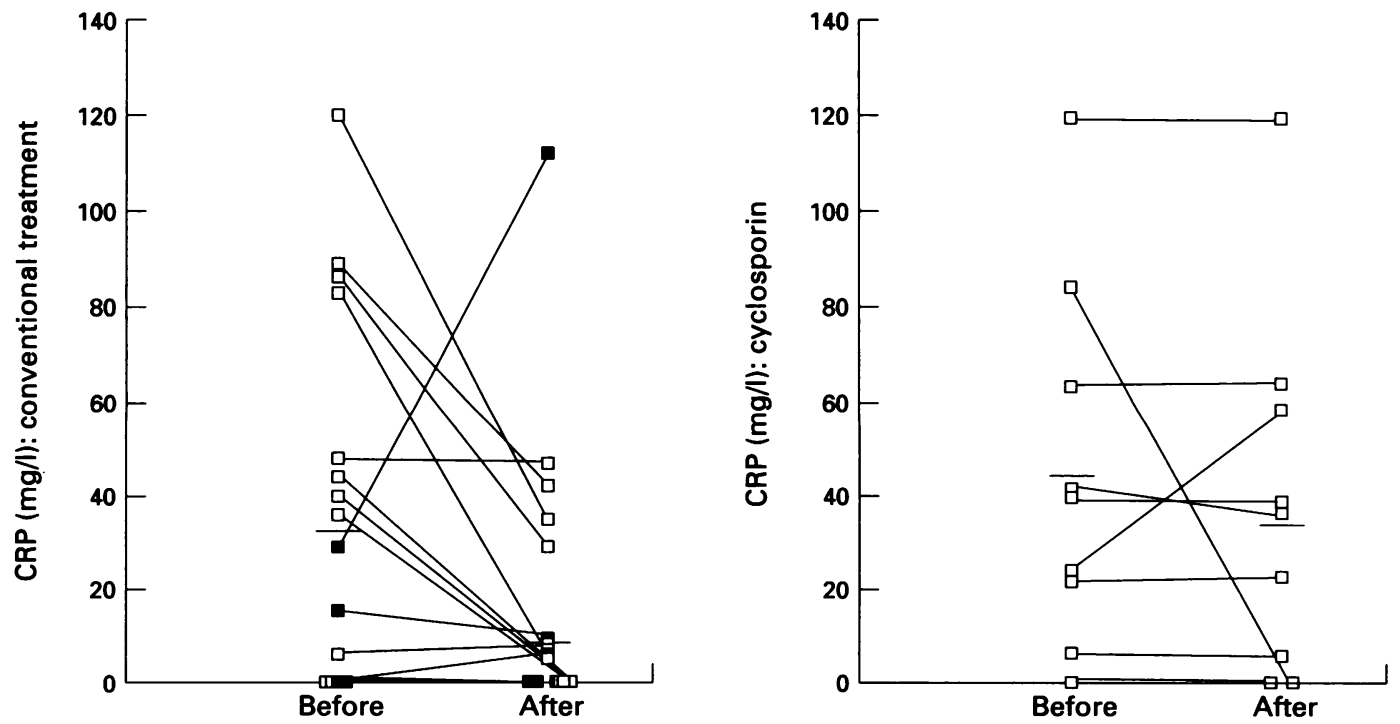

Figure 3 Changes in CRP concentrations before and after treatment. Filled squares indicate corticosteroid treated patients. 


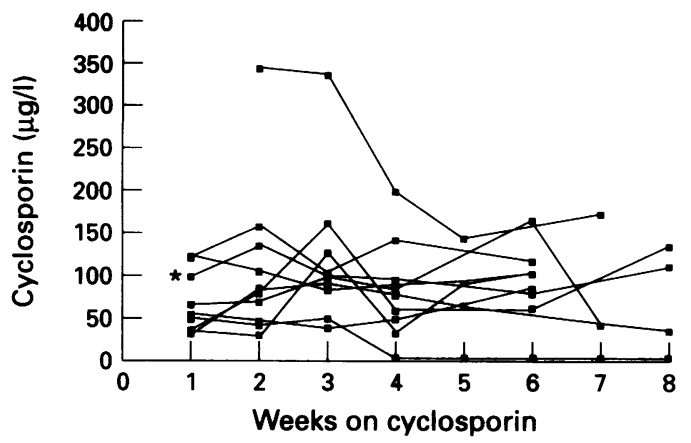

Figure 4 Serial blood trough cyclosporin concentrations in individual patients; * the child withdrawn from the study.

cyclosporin who were rebiopsied improved (two to normal), compared with eight out of 13 $(62 \%)$ treated conventionally (five to normal). There were no specific histological features which improved. This was not significantly better than conventional treatment, $p=0.34$ (Fisher's exact test).

CHANGES IN ESR AND CRP (FIGS 2 AND 3) In the cyclosporin group there was actually an increase in the median $(95 \% \mathrm{CI})$ change in ESR of $4.5 \mathrm{~mm} /$ hour ( -5.5 to 10.5$)$ compared with a median fall of $11.0 \mathrm{~mm} /$ hour $(-27$ to -0.5 ) in the conventional group (significant, $p=0.045)$. The difference between the changes was significant $(p=0.04)$. There was a median change in CRP of $0(-42.5$ to 17.5$)$ in the cyclosporin group (insignificant, $p=0.92$ ), compared with a median fall of $-20.5(-46.5$ to 0 ) in the conventional group (insignificant, $p=0.08$ ). The difference between the two groups was not significant $(p=0 \cdot 14)$.

\section{SIDE EFFECTS IN THE CYCLOSPORIN TREATED} GROUP

In our group of nine children, the following were encountered: hypertrichosis in four, parasthesiae in three, and decreased GFR in five. Hypertrichosis resolved in all affected children within three months, and the parasthesiae were only a minor irritant.

All children with a diminished GFR were rechecked after a further six weeks when in each case the GFR had returned to normal. None of the other reported side effects were encountered.

\section{CYCLOSPORIN MALABSORPTION}

This occurred to a varying degree and seemed to be related to the extent of small bowel involvement. In the worst case, a girl with extensive small bowel Crohn's disease, the blood concentration fell from an initially low value to be undetectable, despite increasing the dose of cyclosporin stepwise from $5 \mathrm{mg} / \mathrm{kg} /$ day to $12 \mathrm{mg} / \mathrm{kg} /$ day. Figure 4 shows blood cyclosporin concentrations against time for each patient, demonstrating the fluctuating values, despite each child taking the dose strictly at the same time every day and the level being measured one hour before this (that is, a trough concentration).
FOLLOW UP

All patients have been followed up since entry into the study to assess the duration of remission.

\section{Cyclosporin group}

Of the 10 children allocated cyclosporin, one withdrew from the study because of clinical deterioration and two were clinically worse at completion of the study than at entry. Of those who improved, one child is still in remission at 23 months and another child, despite marked improvement, was still sufficiently symptomatic to require corticosteroid within one week of cessation of cyclosporin. The other five children had remissions lasting from one to 12 months, median 4.6 months.

\section{Enteral nutrition}

Of the 10 children allocated enteral nutrition, all 10 entered clinical remission. Of these, three are still in remission at nine, 10 , and 15 months. Two children improved clinically and biochemically but complained of marked stricture type abdominal pains (strictures were evident on their barium studies). Both children underwent strictureoplasty/stricturectomy and have been in remission since: six and 10 months respectively. The remaining five children had remissions lasting between three and 12 months (mean 4.8 months).

\section{Corticosteroids}

The four children receiving steroids entered remission, relapsing after one, one, six, and 13 months respectively (mean 5.2 months).

\section{Discussion}

This study is the first attempt to use cyclosporin in childhood Crohn's disease and the first attempt to rationalise the timing of therapeutic intervention with the proposed mechanism of inflammation in inflammatory bowel disease. In addition, this is one of the few studies to utilise reassessment by endoscopy and mucosal biopsy since Modigliani et al demonstrated that in adults with Crohn's disease only $29 \%$ of patients in clinical remission also achieve endoscopic remission after corticosteroid treatment. ${ }^{16}$

A review of the early experience of cyclosporin, ${ }^{17}$ which looked at 124 adults with Crohn's disease treated at 15 centres showed a marked heterogeneity in the severity of the disease, cyclosporin dose, treatment duration and route of administration, concomitant use of steroids, and evaluation criteria. Response varied from $0 \%$ to $91 \%$ (mean $56 \%$ ), and the best results using oral cyclosporin were achieved with chronic active disease rather than very acute disease.

In addition, early results from the first multicentre, placebo controlled study ${ }^{7}$ in chronic, active disease were encouraging, showing a response rate of $61 \%$ for cyclosporin compared with $33 \%$ for placebo, although the final report 
on this study was less encouraging, concluding that (in active, chronic disease) a short course of cyclosporin does not result in long term improvement. ${ }^{18}$ None the less, it was hoped that this might be different if the disease was treated early. In particular, we hoped to demonstrate a greater proportion of endoscopic and histological healing than demonstrated on patients treated with corticosteroids. ${ }^{16}$

Side effects from cyclosporin usage are a concern, in particular nephrotoxicity. Renal dysfunction is characterised by a dose dependent reduction in renal plasma flow and subsequently in GFR. This results in an increase of serum creatinine concentrations, which may still be within the normal range. Half of our children given cyclosporin suffered a reduction in GFR, but in each case this had returned to normal within six weeks of stopping treatment. None of the children had an increased serum creatinine exceeding 30\% above the baseline value, and therefore no reduction in the dose of cyclosporin was necessary.

Maintaining cyclosporin blood concentrations at a steady state was difficult in several of the children, but remarkably consistent cyclosporin concentrations were achieved as shown in fig 4 by the minor fluctuations in blood values. Meticulous attention was paid to timing of drug dosage and blood sampling. One child with extensive small bowel disease had unmeasurable concentrations of cyclosporin after four weeks despite successive dose increases and insistently compliant parents supervising the child. Intravenous administration would probably be indicated at least in the early stages of treatment if a patient with extensive small bowel disease was to be considered for treatment. Certainly, simple oral administration of cyclosporin would not appear to be a straightforward alternative to the use of oral corticosteroids or enteral nutrition as a first line treatment for all newly presenting cases of (childhood) Crohn's disease, particularly if the small bowel is extensively involved.

In terms of outcome, other groups have suggested that short courses of cyclosporin are not enough ${ }^{18}$ and that longer term, low dose maintenance treatment may be necessary. In our study, cyclosporin produced an increase in the Lloyd-Still index (clinical improvement), and a fall in CRP, but neither was statistically significant. In contrast, the conventionally treated group produced a statistically significant improvement in the Lloyd-Still index and ESR. Comparing the two treatment groups, there was no statistical difference between the median changes in the Lloyd-Still index or CRP, but the median improvement in ESR was statistically better in the conventionally treated group of patients. The length of remission for those receiving cyclosporin does not seem to be an improvement on conventional treatment (particularly enteral nutrition), and may in fact be shorter. Whether low dose maintenance cyclosporin could prolong remission awaits evaluation.

In summary therefore, in our study, cyclosporin produced overall clinical and histological improvement, but these did not reach statistical significance. There was no significant improvement in blood inflammation indices. It did not provide the dramatic breakthrough hoped for, and was not significantly better than conventional treatment. The most important observations were that there was a consistent improvement in histological appearance, and that six out of 10 patients improved clinically on cyclosporin treatment. Cyclosporin may be an addition to our armamentarium against chronic inflammatory bowel disease, but simple oral administration should probably not be a treatment of first choice in children newly presenting with Crohn's disease as it offers no obvious advantage over conventional treatment in terms of length of remission or side effects.

We wish to thank the Crohn's in Childhood Research Association for support of this study and the personal support of Dr S Nicholls.

We also wish to thank Sally Hollis in the department of medical statistics, Hope Hospital, Salford, for her assistance in the preparation of this manuscript.

1 Sedgwick DM, Barton JR, Hamer-Hodges DW, Nixon SJ, Ferguson A. Population based study of surgery in juvenile onset Crohn's disease. Br f Surg 1991; 78: 171-5.

2 Jewell DP, Patel C. Immunology of inflammatory bowel disease Scand f Gastroenterol 1985; 114: 119-20.

3 Strober W, James SP. The immunological basis of inflammatory bowel disease. $f$ Clin Immunol 1986; 6: 415-32.

4 Borel JF, Gunn C. Cyclosporin A as a new approach to therapy of autoimmune disease. Ann NY Acad Sci 1986; 475: apy of autoi.

5 Masuda K, Nakajima A, Urayama A, Nakae K, Kogure $M$, Inaba $G$. Double masked trial of cyclosporin versus colchicine and long term open study of cyclosporin in Behçet's disease. Lancet 1989; i: 1093-6.

6 Allison MC, Pounder RE. Cyclosporin for Crohn's disease. Aliment Pharmacol Ther 1987; 1: 39-43.

7 Brynskov J, Binder V, Riis P, et al. Clinical experience with cyclosporin $A$ in chronically active therapy resistant Crohn's disease. A pilot study. Gastroenterology 1987; 92: 1330.

8 Parrott NR, Taylor RMR, Venables CW, Recard CO. Treatment of Crohn's disease in relapse with cyclosporin A. Br F Surg 1988; 75: 1185-8.

9 Baker K, Jewell DP. Cyclosporin for the treatment of severe inflammatory bowel disease. Aliment Pharmacol Ther 1989; 3: 143-9.

10 Brynskov J, Freund L, Rasmussen SN, et al. A placebo controlled double-blind, randomised trial of cyclosporin therapy in active chronic Crohn's disease. $N$ Engl $\mathcal{f} M e d$ 1989; 321: 845-50.

11 Maglinte DT, Burney BT, Miller RE. Lesions missed on small bowel follow through. Analysis and recommendasmall bowel follow through. Analysi

12 Lloyd-Still JD, Green OC. A clinical scoring system for chronic inflammatory bowel disease in children. Dig Dis chronic inflammatory

13 Cameron N. The methods of auxological anthropometry. In: Faulkner F, Tanner JM, eds. Human growth. New York: Plenum Press, 1978: 35-87.

14 Tanner JM, Whitehouse RH, Takaishi M. Standards from birth to maturity for height, weight, height velocity, and weight velocity: British children, 1965. Part II. Arch Dis Child 1966; 41: 613-35.

15 Sanderson IR, Udeen S, Davies PSW, Savage MO, WalkerSmith JA. Remission induced by an elemental diet in small bowel Crohn's disease. Arch Dis Child 1987; 61: small bow.

16 Modigliani R, Mary J, Simon J, et al. Clinical, biological and endoscopic picture of attacks of Crohn's disease. Evolution on prednisolone. Gastroenterology 1990; 98: 811-8.

17 Feutren G, von Graffentied B. Pharmacology of cyclosporin $A$ and clinical experience in inflammatory bowel diseases. Schweiz Med Wochenschr 1991; 121: 748-53.

18 Brynskov J, Freund L, Norby Rasmussen S, et al. Final report on a placebo-controlled, double-blind, randomised, multicentre trial of cyclosporin treatment in active chronic Crohn's disease. Scand $f$ Gastroenterol 1991; 26: 689-95. 